Article

\title{
Rebuild by Design in Hoboken: A Design Competition as a Means for Achieving Flood Resilience of Urban Areas through the Implementation of Green Infrastructure
}

\author{
Robert Šakić Trogrlić ${ }^{1, *}$, Jeroen Rijke ${ }^{2,3}$, Nanco Dolman ${ }^{4}$ (iD) and Chris Zevenbergen ${ }^{5}$ \\ 1 School of Energy, Geoscience, Infrastructure and Environment, Institute for Infrastructure and Environment, \\ Heriot-Watt University, Edinburgh EH14 4AS, UK \\ 2 Knowledge Centre Engineering and Society, HAN University of Applied Sciences, \\ 6826 CC Arnhem, The Netherlands; j.rijke@han.nl \\ 3 Applied Research Centre Delta Areas and Resources, VHL University of Applied Sciences, \\ \#26a Larensteinselaan, 6882 CT Velp, The Netherlands \\ 4 Royal HaskoningDHV, \#47 Contactweg, 1090 GE Amsterdam, The Netherlands; nanco.dolman@rhdhv.com \\ 5 Water Science \& Engineering Department, IHE Delft Institute for Water Education, \#7 Westvest, \\ 2611 AX Delft, The Netherlands; c.zevenbergen@un-ihe.org \\ * Correspondence: RS36@HW.AC.UK
}

Received: 14 January 2018; Accepted: 19 April 2018; Published: 25 April 2018

\begin{abstract}
The Rebuild by Design (RBD) competition was launched after the devastating impact of Hurricane Sandy, and the winning designs have put a significant emphasis on green infrastructure (GI) as a means of achieving flood resilience in urban areas. Previous research in the field of urban stormwater management indicates that wide-spread implementation of GI remains a challenge, largely due to a lack of understanding of the required governance approaches. Therefore, by using a case study of Hoboken, for which the winning design was developed, this paper explores whether RBD provides governance structures and processes needed for the uptake of GI. Semi-structured interviews and desk study provided the data for an analysis of the presence of factors for supporting the transformative governance needed to facilitate the uptake of innovative solutions. Results indicate that RBD brought a greater change in terms of governance processes when compared to governance structures. In Hoboken, RBD created a narrative for long-term change, put GI as a preferred solution for tackling multiple challenges, and strengthened the local political buy-in. However, pitfalls were observed, such as limited funding provision, lack of regulatory compliance, economic justification and large investments required from public and private parties. The absence of these factors can hinder the overall uptake of the GI solution. Even though the design competition presents a novel approach to the field of resilience development, further steps should be made in understanding how the RBD methodology can be adjusted to provide results of equal quality in different settings (e.g., less developed regions, different governance contexts).
\end{abstract}

Keywords: urban resilience; flooding; governance; green infrastructure; Hoboken; Rebuild by Design

\section{Introduction}

In the past, urban areas have been perceived as "safe havens" providing shelter from the impact of natural hazards. However, the modern recognition is that cities are seen as hotspots of disasters and risks [1]. Climate change and its impact will significantly affect cities and their populations, infrastructure and economic activities [2]. The devastating impacts of Hurricane Katrina (2005) in New 
Orleans and Hurricane Sandy (2012) in the greater New York Metropolitan Area, exemplified to what extent cities of today are vulnerable and susceptible to losses. More recently, in 2017, the same message has been conveyed through Hurricane Harvey and Hurricane Irma.

This paper focuses on urban water systems to manage pluvial flooding due to excessive rainfall, insufficient drainage capacity, inadequate planning and how these systems may impact the characteristics of the built environment and vice versa. It is widely acknowledged that these systems are under increasing threat due to several factors, such as climate change, urban population growth, pollution, limited resources and aging infrastructure [3,4]. These pressures are expected to increase flood risk in urban areas and further degrade the health of open water ways around the globe [5]. Resilience has emerged as an approach to deal with such pressures. In urban areas, it is often envisioned as the ability to absorb, adapt and respond to changes in order to provide a predictable performance of an urban system under a wide range of often unpredictable circumstances [6]. With respect to urban flood risk management, resilience refers to the ability to recover from flooding and to adapt to changing probabilities and consequences of flooding as well as to seize opportunities that may emerge over time. Liao [7] stated that the resilience "can be conceptualized as the capacity to remain in a desirable regime while experiencing a flood", thus adding the characteristic of withstanding the disturbance. Salinas Rodriguez et al. [8] added that the term resilience to flooding also incorporates social, institutional and economic aspects. Thus, the operationalization of resilience in urban areas is not easy to achieve $[9,10]$.

After the devastating impact of Hurricane Sandy on the greater New York City area in 2012, the Rebuild by Design (RBD) competition was launched. Recognized as the first among Cable News Networks' (CNN's) Top 10 Ideas of 2013 [11] and awarded the "Most Groundbreaking Federal Challenge or Prize Competition" by the General Services Administration in 2015 [12], the competition delivered innovative designs to enhance flood resilience in the region. RBD has been replicated in several similar initiatives worldwide, such as in the National Disaster Resilience Competition in the United States, the Global Resilience Partnership in areas of Sahel, Horn of Africa, Southeast Asia and Living with Water in Boston [11,13]. Most recently, the call for the "Bay Area Design Challenge" was released, replicating the original RBD competition for the San Francisco Area [14].

One of the projects that came out as a winning proposal in the competition was developed for the highly urbanized parts of the New York metropolitan area Hoboken, Weehawken and Jersey City, New Jersey. There, green infrastructure (GI; e.g., rain gardens and permeable pavements in new parks) was adopted as a key element of a strategy to achieve flood resilience at a district level.

Since the mid-1990s, significant improvement has been made in the availability of advanced technologies for sustainable urban water management (e.g., GI), but still, the transition to actual implementation is hindered [15]. Even though many examples from Australia, the United States, Singapore, and United Kingdom indicate that implementation of GI is possible with strong political commitment, the implementation on a larger scale is still slow and not yet mainstream in urban planning [16,17]. Previous research recognized that the adoption of sustainable urban water systems (i.e., GI) calls for new governance structures and processes [18-20].

With a current movement towards using the RBD model in other regions, it is important to take stock of the lessons from the original competition in terms of enhancing urban flood resilience through GI. Therefore, the aim of this paper, building on the previous recognition of the GI uptake being primarily a governance issue, is to understand whether RBD provided governance structures and processes needed for the wide-spread implementation of GI, using a case study of GI in Hoboken, New Jersey. 


\section{Literature Review}

\subsection{The Process of Rebuild by Design}

After the devastating impacts of Hurricane Sandy (October 2012), the disaster relief effort started. Under President Obama, the Hurricane Sandy Rebuilding Task Force was established, led by the U.S Department of Housing and Urban Development (HUD). In June 2013, this Task Force launched the RBD competition under support by the Rockefeller Foundation and philanthropists. One of the major sources of inspiration for RBD were the "Dutch Dialogues", a series of conferences with local and international experts, initiated in 2006 as a response to the impacts of Hurricane Katrina on New Orleans. These dialogues emphasized the need for a multidisciplinary approach to rebuild Greater New Orleans into a more resilient and attractive city [21].

RBD gathered international expertise to generate strategies to address the resilience challenges in the region through offering innovative designs and presenting a novel approach to policy development. It presented a collaborative effort of government, the private sector, academia, philanthropists and community members. To motivate proposals for development, the federal government allocated the funds for the implementation of the winning proposals by securing $\$ 930$ million, and private sector secured funds for awarding the teams that developed the winning proposals [11]. The list of the proposals that received funding for implementation is presented in Table 1.

As a novel approach and first design competition on this scale (both spatially and by funding available for implementation), RBD applied an innovative methodological framework for enhancing regional long-term resilience. The competition was organized with the vision of catalyzing the transformation of the whole affected region towards being flood resilient [22].

Table 1. List of projects that received funding for implementation.

\begin{tabular}{|c|c|c|c|c|}
\hline Project & Location & Team & $\begin{array}{l}\text { Allocated } \\
\text { Federal Funds } \\
\text { (\$ million) }\end{array}$ & $\begin{array}{l}\text { Green Infrastructure } \\
\text { Presence in Winning } \\
\text { Projects }\end{array}$ \\
\hline $\begin{array}{l}\text { BIG U } \\
\text { Living with the Bay: A }\end{array}$ & New York, New York & BIG TEAM & 335 & Yes (e.g., resilience parks) \\
\hline $\begin{array}{l}\text { Comprehensive Regional } \\
\text { Resiliency Plan for Nassau } \\
\text { County's South Shore }\end{array}$ & Long Island, New York & Interboro Team & 125 & $\begin{array}{l}\text { Yes (e.g., wetlands, } \\
\text { stormwater detention) }\end{array}$ \\
\hline $\begin{array}{l}\text { Resist, Delay, Store, Discharge: } \\
\text { A Comprehensive Strategy for } \\
\text { Hoboken }\end{array}$ & Hoboken, New Jersey & OMA & 230 & $\begin{array}{l}\text { Yes (e.g., green roofs, } \\
\text { permeable pavements) }\end{array}$ \\
\hline Hunts Point Lifelines & Bronx, New York & PennDesign/OLIN & 20 & Yes (e.g., green roofs) \\
\hline Living Breakwaters & Staten Island, New York & $\begin{array}{l}\text { Scape/Landscape } \\
\text { Architecture }\end{array}$ & 60 & $\begin{array}{l}\text { Yes (e.g., stormwater } \\
\text { ponds, wetlands) }\end{array}$ \\
\hline
\end{tabular}

\subsection{The Rise of Green Infrastructure}

Over the past few decades, it is internationally increasingly being recognized that there is a need for change in the way urban water systems are traditionally managed [23-25]. Hence, there is a strong movement in transitioning towards more sustainable urban water systems [18,26]. As argued by Rijke et al. [24], sustainable urban water management systems deliver water resource management systems that are adaptive to change and resilient to extremes. Whilst acknowledging the use of different terms related to sustainable stormwater management in the literature (e.g., green infrastructure, low impact development, sustainable urban drainage systems, and water sensitive urban design) [27], due to the location of the case study, this paper adopts the term GI.

If combined appropriately, GI measures contribute to the resilience of urban areas [4,28]. In the domain of sustainable urban stormwater management, GI provides a wide range of social, economic and 
environmental benefits $[29,30]$. Switching from grey to green infrastructure in urban areas is generally associated with additional social, educational, economic and environmental improvements [31]. Hence, GI serves larger sustainability goals rather than stormwater management alone. GI plays an important role in the field of flood risk management in urban areas, and its potential for flood risk reduction has been demonstrated in numerous studies. For instance, Liu et al. [32] have investigated the impact of GI on a typical neighborhood in Beijing and have found that by implementing integrated GI, runoff of a five-year return period storm has been 100\% reduced. In Augustenborg and Malmo in Sweden, GI has reduced stormwater runoff by 50\% [33]. A recent study by the European Environment Agency [34], based on several European case studies, shows that GI can mitigate floods in a cost-efficient way, when compared to traditional solutions. The effectiveness of GI in managing floods in urban areas is amongst others strongly dependent on the local geophysical and hydrological factors [30].

In the United States, the concept of GI as a way to manage stormwater and reduce water pollution has been applied since the early 1990s [35], and nowadays, the Environmental Protection Agency is increasingly promoting GI through regulation [36]. Cities such as Philadelphia (through the Green Cities and Clean Waters) and Oregon (e.g., Green Streets Programme) serve as examples of city-wide scale application of GI. Their success has largely been achieved through the introduction of several initiatives, such as stormwater charge discount programmes, demonstration projects, the requirement of on-site stormwater management for new development and redevelopment, financial incentives, and a progressive stormwater regulation at municipal level [29].

While the body of scientific knowledge of advanced GI technologies is growing, the development of an evidence base for deploying GI is lagging behind [37]. There is an urgent need to have access to information on examples of local success which demonstrate stormwater practices [4,38,39]. Even though the need for a new paradigm is increasingly being advocated, decision-makers across the globe continue to support traditional ways of dealing with stormwater management, rather than promoting innovative technologies and approaches [23]. Still, the favored approach to urban drainage remains pure conveyance to the nearest water body or pond [16,39]. An overview of barriers to implementing GI is presented in Table 2. The identified barriers are numerous and partly of technical origin, but the common denominator in publications on GI centers around socio-institutional aspects [18-20], since innovative stormwater management calls for an alternative to the traditional way of managing and governance of these systems. A typical feature of GI is also that they are highly context specific, as mentioned above, which implies that every case study is unique and cannot be transferred to others since function is dependent on local characteristics.

Table 2. Barriers to green infrastructure implementation as identified by various authors.

\begin{tabular}{cl}
\hline \multicolumn{1}{c}{ Author } & \multicolumn{1}{c}{ Barriers } \\
\hline Roy et al. [40] & $\begin{array}{l}\text { (1) lack of empirical data on performance and costs of measures; (2) deficiency in technical } \\
\text { standardization and guidances; (3) unclear and fragmented responsibilities; (4) lack of } \\
\text { institutional capacity; (5) lack of legislative mandate; (6) lack of funding and effective market } \\
\text { incentives; and (7) resistance to change }\end{array}$ \\
\hline Brown et al. [25] & $\begin{array}{l}\text { (1) uncoordinated institutional framework; (2) limited community engagement, empowerment } \\
\text { and participation; (3) limits of regulatory framework; (4) insufficient resources (capital and } \\
\text { human); (5) unclear, fragmented roles and responsibilities; (6) poor organizational commitment; } \\
\text { (7) lack of information, knowledge and understanding in applying integrated, adaptive forms of } \\
\text { management; (8) poor communication; (9) no long term vision- strategy; (10) technocratic path } \\
\text { dependencies; (11) little or no monitoring and evaluation; and (12) lack of political and public will }\end{array}$ \\
\hline Lee at al. [16] & $\begin{array}{l}\text { (1) lack of understanding among stakeholders; (2) lack of common standards, guidelines and } \\
\text { technical skills; (3) limited research and knowledge; (4) fragmented stormwater management } \\
\text { institutions; (5) lack of institutional provision; and (6) economic cost }\end{array}$ \\
\hline Abhold et al. [37] & $\begin{array}{l}\text { (1) technical and physical; (2) legal and regulatory; (3) financial; and (4) community and } \\
\text { institutional barriers }\end{array}$ \\
\hline
\end{tabular}


Table 2. Cont.

\begin{tabular}{cl}
\hline \multicolumn{1}{c}{ Author } & \multicolumn{1}{c}{ Barriers } \\
\hline Cettner et al. [19] & $\begin{array}{l}\text { (1) insufficient practical knowledge; (2) missing support (organisational, scientific, local } \\
\text { community); (3) lack of resources and knowledge; (4) ineffective relations and networks; and } \\
\text { (5) discrepancies between interest groups }\end{array}$ \\
\hline & $\begin{array}{l}\text { (1) Community perceptions, buy-in, ownership and understanding of GI; (2) willingness to } \\
\text { pay/sell; (3) how to change policy support for GI; (4) future governance of GI; (5) keeping GI on } \\
\text { the agenda and promoting interagency working; and (6) including climate change in } \\
\text { policy/design standards }\end{array}$ \\
\hline & $\begin{array}{l}\text { (1)Negative past experiences; (2) low priority and/or competing priorities; (3) future land use and } \\
\text { climate; (4) political leadership and champions; (5) lack of available space; (6) responsibilities and } \\
\text { ownership;(6) institutional capacity and expertise; (7) behaviours and cultural; (8) physical } \\
\text { science/engineering uncertainities; (9) legislations, regulations and governance; (10) monetizing } \\
\text { the multiple benefits; (11) maintenance and adoption; (12) issues with partnership working; } \\
\text { (13) ineffective/lack of communication; (14) funding and costs; (14) lack of knowledge, education } \\
\text { and awareness; and (15) reluctance to support new practices }\end{array}$ \\
\hline
\end{tabular}

\subsection{Green Infrastructure Implementation as a Governance Issue}

In the field of urban water governance, three dominant governance approaches are recognized: hierarchical, market and network governance [40]. Hierarchical governance is characterized by formal institutional patterns, lack of stakeholder participation and inflexibility in terms of learning [40,41]. Market governance approaches, by translating private sector management principles to public sector, focus on the efficient allocation of resources, empower citizens and introduction of competition and privatization [42,43]. Network governance is a form of governance where multiple stakeholder groups (public, private and civil actors) interact and as an outcome, develop self-organizing tendencies [43]. This approach is increasingly being advocated as a dominant approach in delivering sustainable water management [41]. RBD can be considered an outing of network governance because it was set up for knowledge exchange amongst multiple "expert" and community actors to develop strategies for urban flood resilience.

Whilst in governance literature importance is placed on facilitating learning through a different approach to institutional design [44], some have seen an opportunity in creating a hybrid governance approach as a combination of standard hierarchical, market and network governance approaches [40], where governance arrangements are a mixture between network and hierarchical approaches and market governance instruments. An analysis of the uptake of stormwater harvesting and reuse schemes in Australia demonstrated how multi-level governance approaches comprised a mix between centralized-decentralized and formal-informal governance, proved to be effective in closing the strategic policy planning-implementation gap [24]. Van de Meene et al. [40] argued that current scholarly work lacks understanding of a setup of governance approaches that facilitates delivery and practical implementation of innovative urban water management solutions (such as GI). The dynamics of governance systems and continuous interactions between different actors create uncertainties that can be addressed through active learning in the process, stakeholder participation and self-organization of governance systems [45].

Led by the idea of a lack of prescriptive approaches for delivering adaptive governance in practice, Farrelly et al. [46] developed practical guidance for supporting transformative governance by identifying eight enabling socio-institutional factors, namely: (1) narrative, metaphor and image; (2) regulatory and compliance agenda; (3) economic justification; (4) policy and planning frameworks and institutional design; (5) leadership; (6) capacity building and demonstration; (7) public engagement and behavior change; and (8) research and partnership with policy and practice. Factors 1-4 refer to governance structures, whereas factors $5-8$ refer to governance processes. Governance structures describe different arrangements of institutional design, whereas governance processes are concerned with managing those [47]. Transformative governance refers to a governance approach that has "the capacity to shape non-linear change in complex systems of people and nature. (...). The goal of transformative governance is to actively shift a socio-ecological system to an alternative and more desirable regime by altering the 
structures and processes that define the system" [47]. Even though this presents an attempt at developing a set of operational components of governance practices needed to support innovation, there is a knowledge gap on how (if at all) these elements can be combined in one approach. This analysis aims to explore to which extent the elements identified by Farrelly et al. [46] are contained in the RBD planning approach for GI as an innovative approach to stormwater management in Hoboken.

\section{Methodology}

\subsection{Case Study Research Design}

The paper adopted a case study research design [48]. Even though RBD resulted in seven winning case studies, this research focuses exclusively on the case study of GI in Hoboken. Hoboken was chosen for three main reasons. Firstly, the scope of the plans that were developed through RBD went beyond mitigation of hurricane-induced risks. Instead, a more comprehensive strategy for flood resilience was developed by Team OMA (OMA, Royal HaskoningDHV, Balmori Associates and HR\&R). The name of the strategy is "Resist, Delay, Store, Discharge: A Comprehensive Urban Water Strategy for Hoboken" (RDSD). The terms "Resist, Delay, Store, Discharge" indicate (respectively): (R) hard infrastructure for protection against storm surges; (D) series of GI for the delay in the runoff; (S) storage areas for excessive rainfall across the City; and (D) discharge pumps. In this paper, the Rebuild by Design (RBD) is used to reflect to a process of the RBD design competition, whereas Resist, Delay, Store, Discharge (RDSD) is used to reflect to the outcomes of the actual winning RBD project in Hoboken. Secondly, the project team had good existing contact among stakeholders in Hoboken. It should be noted that one of the co-authors was a member of Team OMA on behalf of Royal HaskoningDHV. His contribution to this paper was to provide access to the initial set of interviewees and project documentation and to validate the findings from his personal experience in the project. Thirdly, in-depth analysis of one case study was suited to the project logistics (e.g., time and funding available for research, and ease of access to stakeholders).

\subsection{Case Study Area}

In Hoboken, two main sources of flooding are coastal flooding from the Hudson River and pluvial flash flooding when excessive rainfall coincides with a high tide on the Hudson River [49,50]. The flooding can be attributed to several factors, the main factor being a high level of imperviousness, low lying topography, and a combined sewer system with insufficient capacity during wet weather. Modern Hoboken is built on land reclaimed from the Hudson River. During rainfall episodes, there are approximately 100 combined sewer overflows (CSOs) per year discharged into the Hudson River through seven outfalls. This represents a serious environmental issue and, in the light of upcoming federal regulations, the number of CSOs are expected to be decreased to four per year [50]. The flooding problem, coupled with an overtaxed combined sewer system and lack of open space in the city, asks for a new planning approach for the uncertain future. Prior to RDSD and Hurricane Sandy, resilience was not as high on planning agendas of local decision makers and little significant emphasis was given to GI as a mean of providing multifunctional solutions to a series of challenges.

\subsection{Data Collection and Analysis}

The analysis is based on the analysis of interview data and document review, thus creating a mixed research approach. Twenty-one semi-structured interviews were conducted with urban water management stakeholders in Hoboken. Semi-structured interviews were a preferred technique because they allow flexibility by discussing specific aspects and provide the interviewer with new knowledge through analysis of the interviewee's point of view [48]. The interview questions were designed to cover the following topics: (1) local context in Hoboken (governance, planning, institutions, budgets, regulation, projects); (2) drivers for GI implementation in Hoboken; (3) hindering factors in implementation process; and (4) the role of RDSD in delivering flood resilience in Hoboken. 
The initial list of contacts was developed based on the connections made by Team OMA during the RBD competition. After the initial contacts, additional interviewees were identified based on a snowballing technique, essentially meaning that initial participants proposed interviewees that have experience and knowledge relevant to the project [48]. Interviewees represented a range of different backgrounds and involvement in the process and covered local decision makers, state and federal representatives, developers, academia, non-profit organizations, drainage utility owners, transportation officers, and engineering and planning consultants. In addition, an extensive document review was performed to analyze the local context and the RBD process. To ensure high quality of data, desired information was extracted from peer-reviewed scientific literature, existing legislative documents, guidelines and documents provided by United States Environmental Protection Agency, existing development strategies in Hoboken (e.g., Hoboken Master Plan), and information published by local authorities, the State, project developers and online media. In addition, the review included a detailed examination of the RBD and RDSD documentation.

Coding was used to analyze the collected data, by assigning a code to each portion of text to detect similar information provided through the interviews. The codes used were both analytical (i.e., related to the specific research aims investigated, e.g., outcomes of RDSD in Hoboken) and descriptive (i.e., related to the themes identified, e.g., drivers for GI implementation). After the generation of initial codes and sub-codes, a list of "master" codes (i.e., themes) has been developed. It is important to notice that coding is an iterative process; thus, codes have been refined during the analysis. An identical coding strategy was imposed both for the primary data sources (i.e., interviews) and secondary data (i.e., desk document review). To secure the contextual meaning of the interviews, the authors coded sentences and portions of text. The employed coding strategy allowed for an analysis process that resulted in the in-depth analysis of the existing flood resilience planning in Hoboken, the position of GI, and the role played by RDSD. Research findings were also validated by representatives from the RBD team.

\section{Results}

RBD, with its focus on innovation and nature-based solutions, emphasized GI as a preferred option for stormwater management from the outset. In order to understand governance structures and processes, this section looks into the existing planning for flood resilience in Hoboken and details the outcomes delivered by RBD in Hoboken. Based on understanding the change brought to the status-quo, outcomes are discussed through the application of the framework developed by Farrelly et al. [46].

\subsection{Planning for Flood Resilience in Hoboken}

According to the interviewees, prior to RDSD, flood risk management in Hoboken was based on planned construction of "wet weather" discharge pumps to alleviate inundation in the streets and emergency management. The funds for construction of wet weather pumps were secured by the City, whereas operation and maintenance is carried out by the private owner of the drainage system: North Hudson Sewerage Authority (NHSA). This indicates the cooperative relation between core urban water management stakeholders in the City, further reinforced by the overlap between the City's interest in reducing flooding and the NHSA's interest in reducing CSO events.

Even prior to Hurricane Sandy, GI was seen as an inherent part of the City's planning strategy. For instance, Hoboken's Master Plan recognizes the flooding issue and is the first mention of GI as a way of securing more green space in the City together with providing additional benefits (e.g., flood alleviation, urban heat island mitigation) [51]. This idea was further developed in the Master Plan Reexamination Report in 2010, where greening the City was seen as the Mayor's priority and the creation of the Green Element of the Master Plan was advised. However, both planning documents offered only narratives, without detailed operationalizing specifications and instruments. Since a large part of Hoboken is designated as a redevelopment zone, this land is a seen as a window of opportunity for incorporating GI. 
In the aftermath of Hurricane Sandy, several important initiatives for addressing the flooding issues were created. Firstly, a process of developing a Community Resilience Plan by the local government, aimed at addressing vulnerabilities and developing long term community resilience to disastrous events. Secondly, the Green Infrastructure Strategic Plan proposed a conceptual framework for a GI network [52]. However, according to the interviewees, the most important step forward in planning for GI was Hoboken being heavily impacted by Hurricane Sandy and being a case study in one of the six winning proposals of RBD—the RDSD project developed by Team OMA.

Even though it is evident that there was awareness and initial political support for mitigating the flooding effects in Hoboken, it was not until Hurricane Sandy that a recognition of a need for change fully emerged. Sandy and its devastation acted as a trigger and accelerator for finding a solution. As examples from this section indicate, Hoboken has put a particular focus on recovery and resilience planning since Hurricane Sandy.

\subsection{Outcomes of Rebuild by Design in Hoboken}

The interview analysis indicates that direct contributions of RBD to enhancing resilience to flooding consist of impulses for ongoing planning processes and the allocation of funds for implementing a part of RDSD.

During the competition, a diagnostic approach was taken to identify all the challenges in the area and to propose innovative solutions. The outcomes created long-term goals and visions, provided a new visual identity and enhanced flood risk management planning. The new approach to achieving resilience to flooding integrated engineering, urban planning, and policy development, and revealed the need for new financial mechanisms to fund projects. The designed flood risk management strategy embraced the vision of accepting water as a resource and an integral part of urban livability, rather than relying on traditional solutions. Hoboken of the future is envisioned as a greener city whose flood protection is multifunctional, serving its original purpose but also providing additional amenities (e.g., recreational opportunities, decrease in CSOs per year, enhanced social capital). According to the local decision-makers and planners, a big step forward was in understanding the potential of GI as a cost-effective alternative to an aged combined sewer system, as "an alternative that is more financially feasible" (interviewee from the state government). An interviewee from the federal government explained:

"Looking at the cost savings, the co-benefits of putting in green infrastructure as opposed to just doing grey infrastructure, it is really important.(...) New York City, Philadelphia, a lot of municipalities have documented costs savings by replacing some of their grey with green".

Even though all the proposed solutions are on the "landscape architecture level of design" (interviewee from a consultancy) and more detailed planning will be done in the next phase of the project, the first decisive step towards resilient Hoboken has been taken with RDSD. In the meantime, interviewees stated that the municipality is working on delivering the first Resilience Park and incorporating the findings from RDSD, the Green Infrastructure Strategic Plan, plans for designated redevelopment areas and the master plan. As previously mentioned, prior to RBD planning of resilience to flooding was encouraged through a narrative, whereas RDSD provided a more structured vision.

U.S. Department of Housing and Urban Development awarded \$230 million to the State of New Jersey through the "Community Development Block Grant Disaster Recovery Funds" to implement the Strategy. The availability of these funds presents a unique opportunity to upgrade the coastal defense, build protection against a once per 500-year storm surge event and create a more attractive coastline for the local residents. As such, the current focus is on implementing the Resist part of the solution. As explained by the interviewee from the local government:

"... we have a one-time opportunity to build an enormous levee along our coastline to protect the city from the future storm surges and sea level rise, so we want to invest that 230 million into the Resist strategy first. If there are any funds left, we would invest it in other parts". 
The funding for the other parts (Delay, Store and Discharge) is not secured, and the financial resources are to be found in other streams. Thus far, Hoboken received significant resources for planning and delivery of the projects through grants and loans. An interviewee from a non-governmental sector complimented the local government for "seeing advantage of the grants and competitions that were available and putting resources in to do that', and another interviewee states that the mayor 'directed her staff to spend a lot of time getting all these grants like Rebuild by Design (...)".

In addition to enhanced planning and funding for the implementation, having a comprehensive strategy and ambition created an image of the city as a frontrunner in flood resilience efforts. In March 2015, it was named as one of the United Nations Office for Disaster Risk Reduction (UNISDR) Role Model Cities for its flood management practices and RDSD urban water strategy, being only the second city in the US (after San Francisco) to receive this recognition [53].

The interviewees unanimously agreed that RDSD created several important drivers for further development. The main driver for enabling city-wide implementation of GI is the presence of strong political buy-in, leadership, and commitment at the local level. Interviewees believe that the current governing body is seeing GI as a real opportunity and is allocating significant financial and human resources to the implementation. A local government representative stated:

"The Mayor of Hoboken is $110 \%$ behind green infrastructure and she wants it, she wants to add open space and parks in the city, she wants to reduce flooding and improve environmental quality, she wants to improve property values. So she is in favor of it."

Furthermore, some of the interviewees believe this is distinguishing Hoboken from most of the communities in New Jersey, where political commitment is not present. As a representative from the local non-governmental organization pointed out:

"In other towns, the leadership is not there. Mayor is not driving it and you are trying to get the community to help push the mayor along because it (GI) is not mandated under regulation or law that they have to do this."

Further roots of this driver are the needs of the community for more open space, and localized flooding. Interviewees pointed out that the strong political buy-in is exemplified through approvals of the City Council for applications for low-interest loans from the New Jersey Infrastructure Trust, land acquisition in redevelopment zones, grant applications and cooperation demonstrated while strategies were being developed. However, next to these drivers created after RDSD, interviewees see an important external driver that can move the process forward: a need to comply with the federal regulations and decrease the yearly number of combined sewer overflows.

Despite the recognition that RDSD created a strong momentum for solving the problem in Hoboken in the aftermath of Hurricane Sandy, the most challenging part is yet to start: wide-spread implementation. Interviewees stated that the proposed strategy is comprehensive and on the scale of an urban district, requiring significant investments and future dedication. Even though significant progress (previously presented) has been made, the interviewed stakeholders have identified a range of barriers to the actual realization of the strategy, as presented in Figure 1. It is important to notice that the identified drivers and barriers are related to the implementation of Delay and Store parts of the RDSD (i.e., GI), since these are a new and not previously applied approaches in Hoboken, as well as a part of the RDSD that will not be funded through the prize funds. 

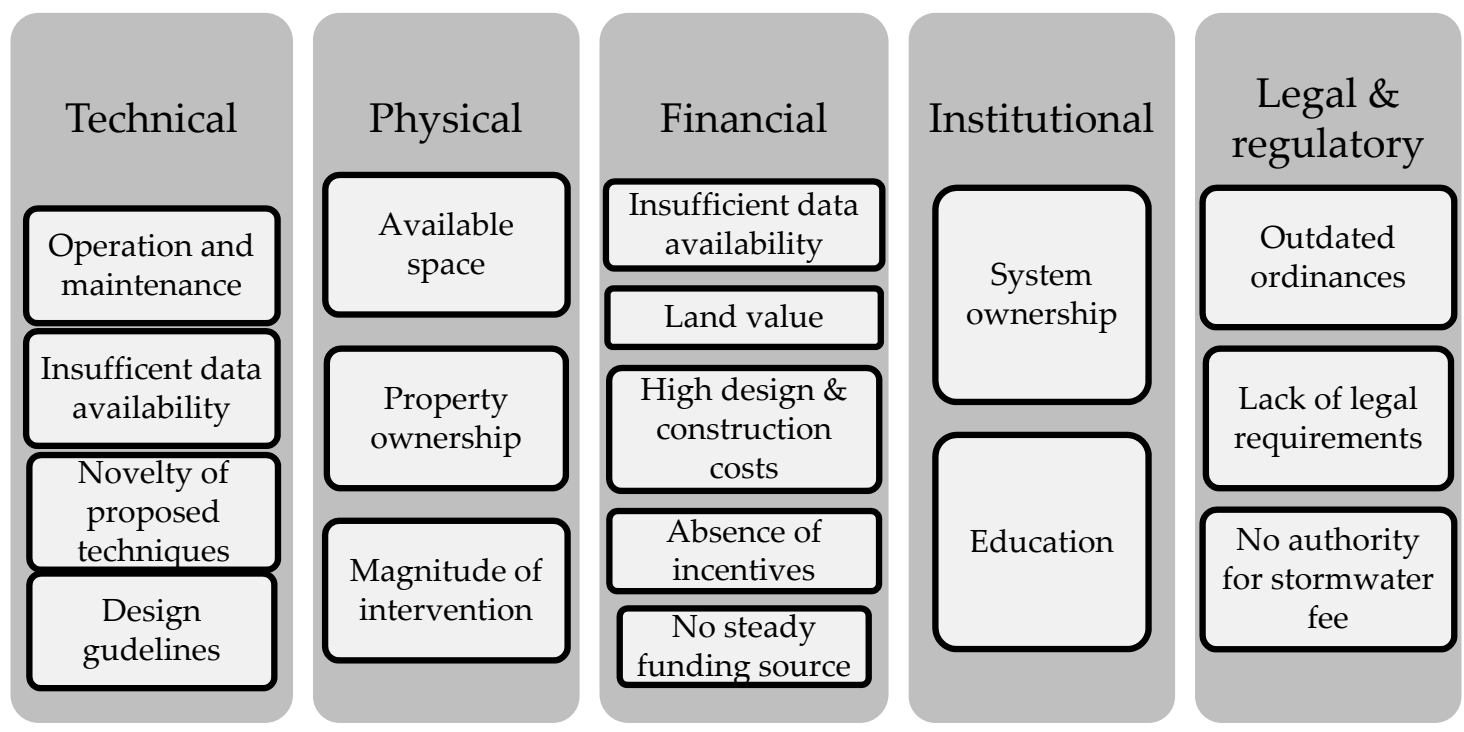

Figure 1. Barriers for the implementation of the Delay and Store parts of the RDSD, as identified by interviewees

\subsection{Rebuild by Design, Governance and the Uptake of Green Infrastructure}

In the Literature Review, the identified eight needed factors for enabling and facilitating change and innovation uptake by Farrelly et al. [46] were presented. This section provides critical analysis of the coded interviews on how these structures and processes governance factors were delivered through GI component of RDSD in Hoboken.

\subsubsection{Governance Structures}

Even though Rebuild by Design was triggered by Hurricane Sandy, the approach taken resulted in a state of the art strategy that went beyond simple rebuilding and increasing the level of protection for the future hurricanes. It provided a platform for designing a solution that addresses multiple challenges in a comprehensive manner. Farrelly et al. [46] argued that a clear vision is important to engage the stakeholders. However, interviewees stated that the RBD approach went a step further by undertaking serious efforts to involve the community while developing the designs. Thereby, it was ensured that the developed RDSD Strategy is representative of the needs of local community, thus creating the ownership of the solution. RDSD created a clear vision and demonstrated a transformational potential of Hoboken.

Even though the RDSD created a long-term vision for Hoboken, it did not contribute to the regulatory and compliance agenda nor provided sound economic justification for GI when compared to traditional infrastructure. However, the project is just entering its second stage, through which more detailed planning and research will be done, so advancement in the development of these factors can be expected. During the interviews, stakeholders were repetitively mentioning a need for a more detailed cost-benefit analysis including additional benefits provided by GI. Such an analysis would prove a business case for GI when compared to traditional infrastructure. As an interviewee pointed out, there is a need for an analysis that would clearly identify where 'the highest impact by lowest cost' is and where 'the highest value of implementation is'. Another suggestion was setting a clear performance target that would allow for constant adjustment in managerial action. The RBD approach, by requiring extensive collaboration, created a nexus between the key urban water management stakeholders in Hoboken.

The approach delivered through RBD and RDSD influenced planning practice and policy creation in Hoboken to a great extent. As a direct consequence of Hurricane Sandy and a direct/indirect consequence of RDSD, several planning initiatives were undertaken. These resulted in a set of policy 
recommendations (e.g., retention standards for stormwater, and zoning codes update) that could promote GI implementation and contribute to overcoming some of the barriers (Figure 1).

\subsubsection{Governance Processes}

The fact that one of the key actors for the initiation of RBD was from the federal government level assured strong leadership in the process. The intensive cooperation between the design team and local government in Hoboken led to the legitimacy of RDSD. As stated before, stakeholders were identifying strong leadership from the local mayor as a key force in moving forward with the GI implementation. The competition attracted leaders from the industry and served as a raising awareness activity in the community.

GI, as a preferred option for stormwater management in RDSD, is an innovative approach in Hoboken. RDSD emphasized the importance of demonstrating the concept through the delivery of demonstration projects [50] and this was further confirmed in the interviews. However, the question of whether there is an established approach to understanding where the demonstration projects could deliver most benefit and whether there is a professional capacity for delivering and maintaining these projects arises. In addition, the RDSD did not foresee any funding for demonstration. As stated earlier, partial funding is available only for the coastal defense. To implement the other parts of RDSD, significant public and private resources will be needed. Hence, there is a realistic threat that RDSD will not be fully implemented unless the innovative funding mechanisms are created and/or private sector funds leveraged.

By involving the public while creating the designs, community drivers were considered (e.g., less flooding, and more green space). The evaluation of the RBD competition done by Urban Institute stated that the community involvement increased the awareness of the problem and emphasized the needs for a solution [54]. RDSD places many GI measures on private properties. Thus, having involved and aware residents (i.e., private property owners) can contribute to the rate of implementation of GI in the future and will require a behavioral change.

From the very idea of establishing the competition, the importance of research and partnerships with policy and practice has been identified. All of the design opportunities have been developed as a result of the extensive collaborative research process [11] and by working closely with local decision-makers, the connection with policy was established. Even so, some of the interviewees proposed the necessity for establishing a partnership with academic institutions (e.g., Stevens Institute of Technology, Rutgers University) that would move the process of implementation forward.

\subsubsection{RBD, Governance and Wide-Spread GI Implementation}

Whilst some of the discussed factors identified by Farrelly et al. [46] in the previous section were a constitutive part of the RBD approach and RDSD in Hoboken (e.g., clear vision, leadership, and research-policy partnerships), others were partially or completely lacking (e.g., regulatory and compliance agenda, and economic justification). The presence of any additional factors, other than those proposed by Farrelly et al. [46] was not observed. It is apparent that the RBD approach contained more factors that fall under the term of governance processes than governance structures. However, as argued by Farrelly et al. [46] all the proposed enabling factors need to be aligned to enable widespread change in the system (i.e., implementation of GI on a city-wide scale). By creating a narrative and long-term vision, RDSD set a foundation for a paradigm change in the way the system was managed in Hoboken, which can be seen as crucial for setting a directional path for change [55]. The results indicate that governance processes go ahead of reform of governance structures. This is in line with findings by Rijke et al. [24] on the emergence of stormwater harvesting and reuse in Australia. In that study, it was demonstrated that in the earlier transformation stages informal networks and innovation testing are facilitated by decentralized and informal governance approaches, whereas in the later stages of transformation, centralized governance approaches secure development of legislative frameworks and stabilization of a new state. The study presented in this paper is, to the best of authors knowledge, the first study analyzing the changes to the status-quo brought to urban stormwater management through a design competition. 
The study reveals that design competitions present a novel approach to strategic policy development and have a potential to create a platform for GI, but the translation of the strategies into reality requires significant changes in policy, politics, regulations and financial approaches. The approach developed and applied through RBD challenges the path dependency of delivering urban stormwater management with a single objective in mind. For Hoboken, even though there are many barriers to implementation identified by the stakeholders (Figure 1), detailed planning done through the next phase of the RDSD project and further commitment from the local leaders will decrease the uncertainties connected with GI and help facilitate wider implementation. In addition, learning from successful examples and best practices of GI implementation from the 'champion cities' across the US (e.g., Philadelphia, Portland and Seattle) can provide valuable inputs for reducing stakeholders' perceived barriers for GI implementation and foster the concept of the "city-to-city" learning. For instance, experiences exemplify introduction of the stormwater fee as a steady funding source [56], and introduction of incentives as a way to motivate GI implementation on private properties (e.g., stormwater fee discount, zoning upgrades, awards and recognition programmes) [57]. Furthermore, technical barriers can be overcome with the continued support towards demonstration projects and development of local design guidelines.

\section{Conclusions}

Based on a series of interviews with local experts and stakeholders, the process of RBD was discussed for the City of Hoboken through a lens of changes to governance structures and processes needed for the wide-spread uptake of GI. The results indicate a more significant change in terms of governance processes when compared to governance structures. RBD brought significant enhancement in the planning of flood resilience by setting a stage for GI and creating a long-term vision, secured a political commitment that lead to increased efforts bringing international recognition to Hoboken. The collaboration between the authorities, the private sector and philanthropists created conditions for innovation through the creation and exchange of ideas between international experts and design teams. The present work unveiled that RBD contains some of the components needed to support transformative governance and facilitate implementation of innovative urban stormwater management at the larger scale.

The study revealed that RBD offered a directional path for change in Hoboken and opened up room for innovation. There were several strong points (e.g., intensive public participation, leadership, research policy interface, capacity building and improvement of long-term planning). However, a lack of a regulatory and compliance agenda and economic justification have been observed. The absence of these factors can hinder the overall uptake of the GI solution and desired transformation. Despite the positive impacts of RBD on Hoboken, the implementation of RDSD has only been partly funded. Thus, without innovative financial mechanisms and involvement of private sector, there is a threat that city-wide implementation of GI will be a difficult goal to accomplish.

The findings from this research, indicating the strong aspects and weaknesses of design competitions as a means of achieving flood resilience in urban areas, are applicable for planners and practitioners involved in the current movement of replicating the RBD model in other settings and offer lessons for decision makers interested in GI. The presented research offers a stockpiling of lessons from the original competition and reveals the areas in which improvements are needed to fully facilitate design competitions as a means of delivering transformative change. Even though design competitions present a novel approach to the field of resilience development, further steps should be made in understanding how the RBD methodology can be adjusted to provide results of equal quality in different settings (e.g., less developed regions, different governance contexts). Further research efforts can be tailored towards a full-scale (i.e., including all winning case studies) evaluation of the effectiveness of RBD to deliver a wider scale implementation of GI, through investigating the shifts and changes brought to governance regimes. 
Author Contributions: The paper was written by Robert Šakić Trogrlić based on the result obtained from his research which was done under the close supervision of Jeroen Rijke, Nanco Dolman and Chris Zevenbergen. All co-authors gave ideas for the specific parts of the manuscript and helped to review and improve the paper.

Acknowledgments: This research was financially supported by Royal HaskoningDHV, CRC for Water Sensitive Cities and the European Commission, as part of the Erasmus Mundus MSc Master Programme in Flood Risk Management, all of whom are hereby acknowledged. We thank the Rebuild by Design team, and particularly Tara Eisenberg for their review of a first draft of the paper. Further thanks are directed towards those who offered their precious time to be interviewed. Finally, we thank Annie Visser and Joanne Craven for proofreading the manuscript.

Conflicts of Interest: The authors declare no conflict of interest.

\section{References}

1. Wamsler, C.; Brink, E.; Rivera, C. Planning for climate change in urban areas: From theory to practice. J. Clean. Prod. 2013, 50, 68-81. [CrossRef]

2. Rosenzweig, C.; Solecki, W. Hurricane Sandy and adaptation pathways in New York: Lessons from a first-responder city. Glob. Environ. Chang. 2014, 28, 395-408. [CrossRef]

3. Ferguson, B.C.; Brown, R.R.; Deletić, A. Diagnosing transformative change in urban water systems: Theories and frameworks. Glob. Environ. Chang. 2013, 23, 264-280. [CrossRef]

4. Perales-Momparler, S.; Andrés-Doménech, I.; Andreu, J.; Escuder-Bueno, I. A regenerative urban stormwater management methodology: The journey of a Mediterranean city. J. Clean. Prod. 2015, 109, 174-189. [CrossRef]

5. Pahl-Wostl, C.; Holtz, G.; Kastens, B.; Knieper, C. Analyzing complex water governance regimes: The Management and Transition Framework. Environ. Sci. Policy 2010, 13, 571-581. [CrossRef]

6. Desouza, K.C.; Flanery, T.H. Designing, planning, and managing resilient cities: A conceptual framework. Cities 2013, 35, 89-99. [CrossRef]

7. Liao, K. A Theory on Urban Resilience to Floods-A Basis for Alternative Planning Practices. Ecol. Soc. 2012, 17, 48. [CrossRef]

8. Salinas Rodriguez, C.N.A.; Ashley, R.; Gersonius, B.; Rijke, J.; Pathirana, A.; Zevenbergen, C. Incorporation and application of resilience in the context of water-sensitive urban design: Linking European and Australian perspectives. WIREs Water 2014, 1, 173-186. [CrossRef]

9. Rijke, J.; van Herk, S.; Zevenbergen, C.; Ashley, R.; Hertogh, M.; ten Heuvelhof, E. Adaptive programme management through a balanced performance/strategy oriented focus. Int. J. Proj. Manag. 2014, 32, 1197-1209. [CrossRef]

10. Van Herk, S.; Zevenbergen, C.; Gersonius, B.; Waals, H.; Kelder, E. Process design and management for integrated flood risk management: Exploring the multi-layer safety approach for Dordrecht, The Netherlands. J. Water Clim. Chang. 2014, 5, 100-115. [CrossRef]

11. Gendall, J.; Bisker, J.; Chester, A.; Eisenberg, T.; Davis, S.; Ovink, H. Rebuild by Design; Rebuild by Design: New York, NY, USA, 2015.

12. Rebuild by Design. Available online: http://www.rebuildbydesign.org/rebuild-awarded-mostgroundbreaking-federal-challenge-or-prize-competition/ (accessed on 11 October 2015).

13. Sutton Grier, A.E.; Wowk, K.; Bamford, K. Future of our coasts: The potential for natural and hybrid infrastructure to enhance the resilience of our coastal communities, economies and ecosystems. Environ. Sci. Policy 2015, 51, 137-148. [CrossRef]

14. Rebuild by Design. Available online: http://www.rebuildbydesign.org/our-work/city-initiatives/sanfrancisco-bay-area (accessed on 14 January 2017).

15. Drafting Team of the WFD CIS Working Group Programme of Measures. EU Policy Document on Natural Water Retention Measures; Techical Report-2014-2082; Directorate-General for Environment (European Commission): Brussels, Belgium, 2015. [CrossRef]

16. Lee, S.; Yigitcanlar, T. Sustainable urban stormwater management: Water sensitive urban design perceptions, drivers and barriers. In Rethinking Sustainable Development: Urban Management, Engineering and Design; Yigitcanlar, T., Ed.; Engineering Science Reference; IGI Global: Hershey, PA, USA, 2010; pp. 22-37.

17. O'Donnell, E.C.; Lamond, J.E.; Thorne, C.R. Recognising barriers to implementation of Blue-Green Infrastructure: A Newcastle case study. Urban Water J. 2017, 1-11. [CrossRef] 
18. Brown, R.R.; Farrelly, M.A. Delivering sustainable urban water management: A review of the hurdles we face. Water Sci. Technol. 2009, 59, 839-846. [CrossRef] [PubMed]

19. Cettner, A.; Ashley, R.; Hedström, A.; Viklander, M. Assessing receptivity for change in urban stormwater management and contexts for action. J. Environ. Manag. 2014, 146, 29-41. [CrossRef] [PubMed]

20. Thorne, C.R.; Lawson, E.C.; Ozawa, C.; Hamlin, S.L.; Smith, L.A. Overcoming uncertainty and barriers to adoption of Blue-Green Infrastructure for urban flood risk management. J. Flood Risk Manag. 2015. [CrossRef]

21. USGBC. New Orleans Architects Look to the Netherlands for Ideas on Living with Water. Available online: http:/ / plus.usgbc.org/dutch-dialogues / (accessed on 15 November 2015).

22. Ovink, H.; Boeijenga, J. Too Big: Rebuild by Design's Transformative Response to Climate Change; Nai010 Publishers: Rotterdam, The Netherlands, 2018; ISBN 978-94-6208-315-8.

23. Farrelly, M.; Brown, R. Rethinking urban water management: Experimentation as a way forward? Glob. Environ. Chang. 2011, 21, 721-732. [CrossRef]

24. Rijke, J.; Farrelly, M.; Brown, R.; Zevenbergen, C. Configuring transformative governance to enhance resilient urban water systems. Environ. Sci. Policy 2013, 25, 62-72. [CrossRef]

25. Brown, R.R.; Sharp, L.; Ashley, R.M. Implementation impediments to institutionalising the practice of sustainable urban water management. Water Sci. Technol. 2006, 54, 415-422. [CrossRef] [PubMed]

26. Olorunkiya, J.; Fassman, E.; Wilkinson, S. Risk: A Fundamental Barrier to the Implementation of Low Impact Design Infrastructure for Urban Stormwater Control. J. Sustain. Dev. 2012, 5, 27. [CrossRef]

27. Fletcher, T.D.; Shuster, W.; Hunt, W.F.; Ashley, R.; Butler, D.; Arthur, S.; Trowsdale, S.; Barraud, S.; Semadeni-Davies, A.; Bertrand-Krajewski, J.-L.; et al. SUDS, LID, BMPs, WSUD and more-The evolution and application of terminology surrounding urban drainage. Urban Water J. 2014, 12, 525-542. [CrossRef]

28. Voskamp, I.M.; Van de Ven, F.H.M. Planning support system for climate adaptation: Composing effective sets of blue-green measures to reduce urban vulnerability to extreme weather events. Build. Environ. 2014, 83, 159-167. [CrossRef]

29. USEPA. Green Infrastructure Case Studies: Municipal Policies for Managing Stormwater with Green Infrastructure. 2010. Available online: http://www.sustainablecitiesinstitute.org/topics/water-andgreen-infrastructure/stormwater-management/green-infrastructure-case-studies-municipal-policies-formanaging-stormwater-with-green-infrastructure (accessed on 17 May 2015).

30. Demuzere, M.; Orru, K.; Heidrich, O.; Olazabal, E.; Geneletti, D.; Orru, H.; Bhave, A.G.; Mittal, N.; Feliu, E.; Faehnle, M. Mitigating and adapting to climate change: Multi-functional and multi-scale assessment of green urban infrastructure. J. Environ. Manag. 2014, 146, 107-115. [CrossRef] [PubMed]

31. Barbosa, A.E.; Fernandes, J.N.; David, L.M. Key issues for sustainable urban stormwater management. Water Res. 2012, 46, 6787-6798. [CrossRef] [PubMed]

32. Liu, W.; Chen, W.; Peng, C. Assessing the effectiveness of green infrastructures on urban flooding reduction: A community scale study. Ecol. Model. 2015, 318, 236-244. [CrossRef]

33. European Commission. Towards an EU Research and Innovation Policy Agenda for Nature-Based Solution \& Re-Naturing Cities. 2015. Available online: https:/ / ec.europa.eu/research/environment/index.cfm?pg=nbs (accessed on 22 February 2018).

34. European Environmental Agency. Green Infrastructure and Flood Management: Promoting Cost-Effecient Flood Risk Reduction via Green Infrastructure Solutions. 2017. Available online: https:/ /www.eea.europa. eu/publications / green-infrastructure-and-flood-management (accessed on 22 February 2018).

35. LaBadie, K. Identifying Barriers to Low-Impact Development and Green Infrastructure in Albuquerque Area. Master's Thesis, The University of New Mexico, Albuquerque, NM, USA, 2010.

36. Abhold, K.; Lorraine, L.; Grumbles, B. Barriers and Gateways to Green Infrastructure. Available online: https:/ / issuu.com/savetherain/docs/barriers-and-gateways-to-gi_cwaa (accessed on 22 February 2018).

37. Faivre, N.; Fritz, M.; Freitas, T.; de Boissezon, B.; Vandewoestijne, S. Nature-based solutions in the EU: Innovating with nature to address social, economic and environmental challenges. Environ. Res. 2017, 159, 509-518. [CrossRef]

38. Brown, R.R. 2005 Impediments to integrated urban stormwater management: The need for institutional reform. Environ. Manag. 2005, 36, 455-468. [CrossRef] [PubMed]

39. Roy, A.H.; Wenger, S.J.; Fletcher, T.D.; Walsh, C.J.; Ladson, A.R.; Shuster, W.D.; Thurston, H.W.; Brown, R.R. Impediments and solutions to sustainable, watershed-scale urban stormwater management: Lessons from Australia and the United States. Environ. Manag. 2008, 42, 344-359. [CrossRef] [PubMed] 
40. Van de Meene, S.J.; Brown, R.R.; Farrelly, M.A. Towards understanding governance for sustainable urban water management. Glob. Environ. Chang. 2011, 21, 1117-1127. [CrossRef]

41. Pahl-Wostl, C. Transitions towards adaptive management of water facing climate and global change. Water Resour. Manag. 2007, 21, 49-62. [CrossRef]

42. Bakker, K. From State to Market: Water Mercantilización in Spain. Environ. Plan. A 2002, 34, 767-790. [CrossRef]

43. Rijke, J. Delivering Change: Towards Fit-for-Purpose Governance of Adaptation to Flooding and Drought. Ph.D. Thesis, Department of Civil Engineering, Technical University Delft, Delft, The Netherlands, 2014.

44. Huntjens, P.; Lebel, L.; Pahl-Wostl, C.; Camkin, J.; Schulze, R.; Kranz, N. Institutional design propositions for the governance of adaptation to climate change in the water sector. Glob. Environ. Chang. 2012, 22, 67-81. [CrossRef]

45. Rijke, J.; Brown, R.; Zevenbergen, C.; Ashley, R.; Farrelly, M.; Morison, P.; van Herk, S. Fit-for-purpose governance: A framework to make adaptive governance operational. Environ. Sci. Policy 2012, 22, 73-84. [CrossRef]

46. Farrelly, M.; Rijke, J.; Brown, R. Exploring Operational Attributes of Governance for Change. In Proceedings of the 7th International Conference on Water Sensitive Urban Design, Melbourne, Australia, 2-7 April 2006.

47. Chaffin, B.C.; Garmestani, A.S.; Gunderson, L.H.; Harm Benson, M.; Angeler, D.G.; Arnold, C.A.; Cosens, B.; Kundis Craig, R.; Ruhl, J.B.; Allen, C.R. Transformative Environmental Governance. Annu. Rev. Environ. Resour. 2016, 41, 399-423. [CrossRef]

48. Bryman, A. Social Research Methods, 4th ed.; Oxford University Press: Oxford, UK, 2012; ISBN 978-0199588053.

49. Cruijsen, A.C. Design Opportunities for Flash Flood Reduction by Improving the Quality of the Living Environment: A Hoboken City Case Study of Environmental Driven Urban Water Management. Master's Thesis, Department of Civil Engineering, Technical University Delft, Delft, The Netherlands, 2015.

50. Team OMA. Resist, Delay, Store, Discharge: A Comprehensive Urban Water Strategy; Team OMA: New York, NY, USA, 2013.

51. Hoboken Planning Board. Hoboken Master Plan; Hoboken Planning Board: Hoboken, NJ, USA, 2004.

52. Together North Jersey. Available online: http://www.hobokennj.org/docs/communitydev/HobokenGreen-Infrastructure-Strategic-Plan.pdf (accessed on 11 November 2017).

53. UNISDR. Available online: https:// www.unisdr.org/archive/42762 (accessed on 11 November 2017).

54. Urban Institute. Available online: https://assets.rockefellerfoundation.org/app/uploads/20140610165452/ The-Evaluation-of-the-Design-Competition-of-Rebuild-by-Design.pdf (accessed on 11 September 2015).

55. Wong, T.; Brown, R.R. Transitioning to Water Sensitive Cities: Ensuring Resilience through a new HydroSocial Contract. In Proceedings of the 11th International Conference on Urban Drainage, Edinburgh, UK, 31 August-5 September 2008.

56. Campbell, C.W. Western Kentucky University Stormwater Utility Survey. 2014. Available online: http:/ / www.circleofblue.org/waternews /wp-content/uploads/2015/04/wku_stormwater_survey_ 2014_finalversion.pdf (accessed on 14 March 2015).

57. USEPA. Managing Wet Weather with Green Infrastructure Municipal Handbook: Incentive Mechanisms. 2009. Available online: https:/ / www.epa.gov/green-infrastructure (accessed on 17 April 2015).

(C) 2018 by the authors. Licensee MDPI, Basel, Switzerland. This article is an open access article distributed under the terms and conditions of the Creative Commons Attribution (CC BY) license (http:/ / creativecommons.org/licenses/by/4.0/). 